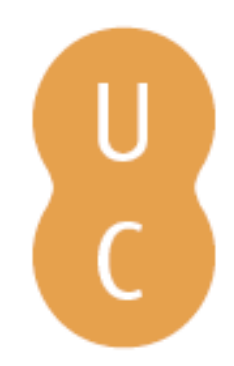

\title{
pombalina
}

\section{Filantropía en la Vida de Catón el Viejo}

Autor(es): $\quad$ Candau Morón, José M.

Publicado por: Imprensa da Universidade de Coimbra; Centro de Estudos Clássicos e Humanísticos

URL

persistente: URI:http://hdl.handle.net/10316.2/32017

DOI: $\quad$ DOI:http://dx.doi.org/10.14195/978-989-8281-17-3_32

Accessed : $\quad$ 26-Apr-2023 05:44:23

A navegação consulta e descarregamento dos títulos inseridos nas Bibliotecas Digitais UC Digitalis, UC Pombalina e UC Impactum, pressupõem a aceitação plena e sem reservas dos Termos e Condições de Uso destas Bibliotecas Digitais, disponíveis em https://digitalis.uc.pt/pt-pt/termos.

Conforme exposto nos referidos Termos e Condições de Uso, o descarregamento de títulos de acesso restrito requer uma licença válida de autorização devendo o utilizador aceder ao(s) documento(s) a partir de um endereço de IP da instituição detentora da supramencionada licença.

Ao utilizador é apenas permitido o descarregamento para uso pessoal, pelo que o emprego do(s) título(s) descarregado(s) para outro fim, designadamente comercial, carece de autorização do respetivo autor ou editor da obra.

Na medida em que todas as obras da UC Digitalis se encontram protegidas pelo Código do Direito de Autor e Direitos Conexos e demais legislação aplicável, toda a cópia, parcial ou total, deste documento, nos casos em que é legalmente admitida, deverá conter ou fazer-se acompanhar por este aviso.

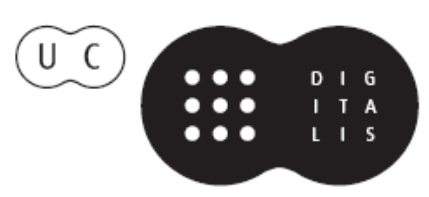




\section{Symposion and Philanthropia in Plutarch}

\section{José Ribeiro Ferreira, Delfim Leão Manuel Troster e Paula Barata Dias (eds.)}

IMPRENSA DA UNIVERSIDADE DE COIMBRA 


\title{
Filantropía en la Vida de Catón el Viejo
}

\author{
José M. Candau Morón \\ Universidad de Sevilla
}

\begin{abstract}
In the Life of Cato Maior Plutarch looks at his main character with an attitude consisting of admiration on one hand, of criticism and blame on the other. The concept of philanthropia represents the key that opens the door to the criticism. Catos's lack of philanthropia is responsible for his philotimia, his deficient autarkeia and his want of sophrosyne. Even his political activity undergoes the effects of this fundamental failure. This paper tries to explore how the structure of the biography reflects the importance that Plutarch assigns to the central flaw of its protagonist.
\end{abstract}

Resultaría problemático incluir la Vida de Catón el Viejo entre las biografías negativas. El modelo más acabado de biografía negativa es probablemente la Vida de Demetrio. Un presupuesto importante de esta obra lo constituye el marco temático que brindan las grandes naturalezas, las naturalezas dotadas tanto para el bien como para el mal que por un error o una serie de elecciones erróneas concluyen en un final desastroso ${ }^{1}$. La teatralidad, entendida como despliegue ostentoso y vacío, es otro de los ingredientes de la Vida de Demetrio ${ }^{2}$. Y por último la esterilidad, la ausencia de realizaciones o mensajes importantes políticos o humanos, es otro componente que Plutarco subraya y parece considerar definitorio de una existencia como la de Demetrio ${ }^{3}$. Nada de esto aparece en la Vida de Catón. Sin embargo, Plutarco alberga fuertes reservas morales contra su protagonista, hasta tal punto que Catón el Viejo parece situarse en un punto intermedio entre los personajes que en las Vidas Paralelas aparecen como modelos a imitar y aquellos otros que destacan ante todo por sus cualidades negativas.

Son dos los pasajes de la biografía que exponen con claridad y con cierto detalle los defectos de la personalidad de Catón. Uno de ellos se sitúa al inicio, en los capítulos 4 y 5 . Plutarco comienza aquí hablando de la tendencia a la economía que despliega su protagonista en distintas facetas de su vida: en el vestido, en la comida y la bebida, en las construcciones de su hacienda, en la compra de esclavos. Catón creía, afirma el biógrafo, que cuando los esclavos envejecen hay que venderlos para no gastar alimento en seres inútiles. Aquí Plutarco hace un alto: tratar así a los esclavos, como si fueran animales, es propio de un carácter rígido para el que la utilidad es el único fundamento

${ }^{1}$ Plutarco toca el tema de las grandes naturalezas (sobre el que teoriza en Ser. num. vind. 551D-552D) no sólo el proemio a las Vidas de Demetrio y Antonio (Demetr. 1.7-8) sino también en Them. 2.7, Nic. 9.1, y Cor. 1.3. Se trata de un tema sobre el que disertan tanto Platón (el pasaje canónico es $R$. 491d-492a; véase también Hp. Mi. 376a) como Jenofonte (Mem. 4.1.4). Tratamientos modernos de la cuestión ofrecen O. Andrei, 1989 y T. Duff, 1999.

${ }^{2}$ Sobre la prominencia de los elementos teatrales en la Vida de Demetrio véase O. Andrei, 1989, pp. 78-82; J. M. CANdau, 1999, pp. 142-3.

3 Véase Demetr. 42.3. Comentario en J. M. Candau, 1999, pp. 143-4. 
de las relaciones entre los hombres ${ }^{4}$. Nuestros buenos sentimientos, sin embargo se extienden hasta el punto de tratar suave y benévolamente incluso a los animales. Con este comentario Plutarco abre una digresión en la que diserta sobre un tema reiterado en su obra y representativo de su personalidad literaria, el afecto hacia los animales ${ }^{5}$. Ya al final, después de comentar varios

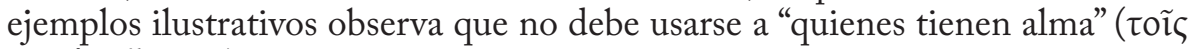

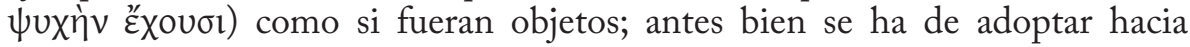
estos un comportamiento dulce y benigno, si no por otra razón para poner en

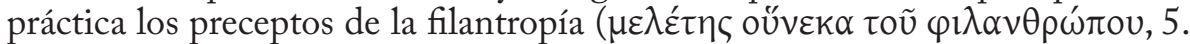
$5)$. El concepto de $\varphi \imath \lambda \alpha v \theta \rho \omega \pi i ́ \alpha$ hace aquí una aparición opaca y, digamos, disimulada. En primer lugar se halla envuelto en el interior de una discusión que comienza hablando de la economía y dedica gran espacio al tema del afecto hacia los animales. En segundo lugar solo lo leemos al final, cuando la digresión está tocando a su fin. Se le invoca, además, como último recurso con

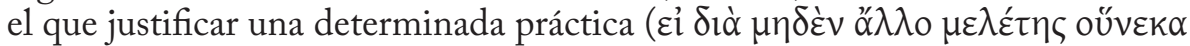

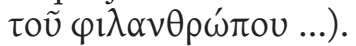

Plutarco asocia en otras ocasiones la liberalidad económica, la falta de avaricia y de preocupación ante el dinero con la $\varphi \imath \lambda \alpha v \theta \rho \omega \pi i ́ \alpha$. Solón, de familia noble, gastó la fortuna de su padre en actos de filantropía y en mercedes ${ }^{6}$. Pelópidas, nacido en el seno de una casa opulenta, socorría con sus riquezas a cuantos lo necesitaban, y todos se acogían a su filantropía y liberalidad ${ }^{7}$. Catón es un homo novus cuya falta de la liberalidad en lo referente al dinero y la riquezas acentúan diversos pasajes de la biografía, incluido un lugar tan prominente como la síncrisis ${ }^{8}$. Ahora bien, al caracterizar esa faceta de su personaje Plutarco, aparentemente, evita el término $\varphi \imath \lambda \alpha v \theta \rho \omega \pi i ́ \alpha$, término que utiliza de manera diríase que marginal, casi como si lo escondiese.

El segundo de los pasajes que disertan con amplitud sobre los aspectos negativos de Catón aparece en el tramo final de la biografía. El capítulo 22 menciona la famosa embajada a Roma en la que participó el filósofo Carnéades. Ante la expectación que el filósofo despierta entre la población romana, Catón se muestra partidario de hacer que todos los filósofos sean conducidos fuera de la ciudad ${ }^{9}$. Tal reacción se debió ante todo a su hostilidad hacia la filosofía y la cultura griegas. Después de brindar algunos ejemplos de este antihelenismo, Plutarco consigna una predicción de Catón, conforme a la cual el estado romano sería destruido cuando las letras griegas penetrasen en sus ciudadanos. Predicción que el tiempo ha demostrado falsa, pues, comenta el biógrafo, la supremacía de Roma ha coincidido con la implantación en el imperio de los

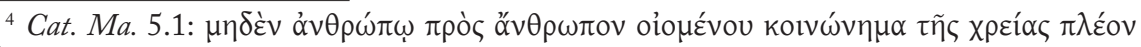

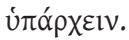

${ }^{5}$ Sobre el tema ouede hallarse información y bibliografía actualizada en J. M. Cervantes Mauri, 2005 y M. T. Clavo Sebastián, 2005.

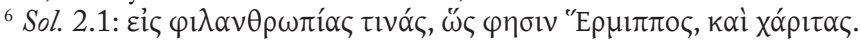

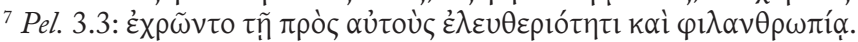

${ }^{8}$ Además del pasaje citado véase Cat. Ma. 21; 31 (4).

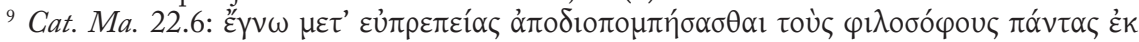

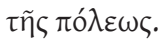


conocimientos y la cultura de Grecia. Un posicionamiento ante la cultura griega como el que aquí se describe, constituye para Plutarco una falta mayor. Así los subraya el capítulo 24, cuya frase inicial presenta la muerte de la esposa y el hijo de Catón como un castigo divino (vé $\mu \varepsilon \sigma ı)$ ) sobrevenido a consecuencia de la actitud antihelénica del personaje. Los aspectos más desfavorables de su personalidad quedan al descubierto, además, en dos episodios que siguen.

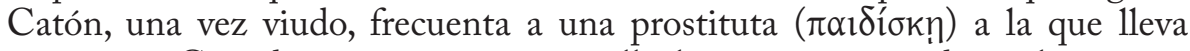
a su casa. Cuando se encuentra con ella la joven esposa de su hijo tiene lugar una situación embarazosa. A continuación Catón contrae su segundo matrimonio con una joven de extracción humilde, hija de uno de sus clientes. Boda bochornosa que, según se dice en la síncrisis, constituye materia para un justificado reproche.

También en este segundo pasaje negativo para el protagonista aparece el término $\varphi \imath \lambda \alpha v \theta \rho \omega \pi i ́ \alpha$, pero, como sucedía en el pasaje anterior, su presencia es subrepticia, de manera que casi pasa inadvertido. Al principio, cuando Plutarco consigna el éxito que obtuvo Carnéades en Roma, añade que sus conferencias

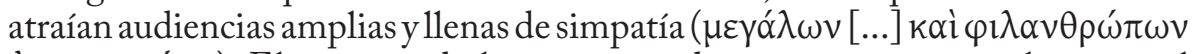

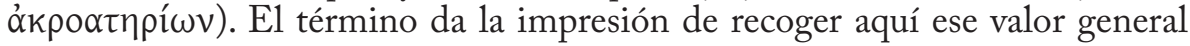
de afecto o empatía emocional con lo humano que estudios recientes le han atribuido, un valor que, por lo demás, resulta característico de la filosofía vital de Plutarco ${ }^{10}$. Ahora bien, en el momento histórico en que escribe Plutarco, $\varphi \imath \lambda \alpha v \theta \rho \omega \pi i ́ \alpha$ puede haber sido un concepto cargado de connotaciones políticas. En el panegírico que Plinio dedica a Trajano, el término bumanitas, la $\varphi \imath \lambda \alpha v \theta \rho \omega \pi i ́ \alpha$ griega, se usa reiteradamente: cualidad propia del hombre, no del dios, la bumanitas es una de las virtudes que distinguen al bonus princeps del dominus e incluso es, se ha afirmado, la cualidad que fundamentalmente alaba Plinio en Trajano ${ }^{11}$. Si se admite que el panegírico de Plinio es exponente de un cambio ideológico que se produce cuando Trajano llega al trono; si se admite asimismo que Plutarco, como Tácito o Dión Crisóstomo, participa plenamente de dicho cambio; si igualmente se acepta, como estudios recientes aseguran, que las Vidas Paralelas sólo se pudieron gestar en el ambiente intelectual propiciado por el ascenso de Trajano ${ }^{12}$ : si todo ello se admite no puede pensarse que $\varphi \imath \lambda \alpha v \theta \rho \omega \pi i ́ \alpha$ sea para Plutarco una palabra más. Al contrario, debe ser, en principio, un término destacado, portador de un fuerte colorido ideológico.

En la síncrisis Plutarco atribuye el vergonzoso segundo matrimonio de Catón a falta de $\sigma \omega \varphi \rho o \sigma u ́ v \eta^{13}$. La parte narrativa que presenta dicho episodio se abre con el tema del antihelenismo del protagonista, un antihelenismo que, al unirse a la hostilidad hacia la filosofía, hacia la medicina griega o hacia

${ }^{10}$ Cf. A. Georgiadou, 1997, p. 69; G. D’Ippolito, 2005, pp. 180-1; S.-T. Teodorsson, 2007, pp.189-90.

${ }_{11}$ Cf. P. A. Stadter, 2002b, pp. 228-9. La búsqueda del término bumanitas en el texto electrónico del Panegírico proporciona siete entradas (2.7.2; 3.4.4; 4.7.1; 24.2.3; 47.3.2; 49.6.1; 71.5.3).

${ }^{12}$ Véase P. A. Stadter, 2002a, p. 6; M.T. Schettino, 2002, pp. 201-5; G. Zecchini, 2002, p. 194.

${ }^{13}$ Cat. Ma. 33 (6).1. 
figuras emblemáticas como Sócrates, produce una impresión de rudeza y ausencia de $\pi \alpha 1 \delta \varepsilon i ́ \alpha$ muy en sintonía con las circunstancias y motivaciones actuantes en ese segundo matrimonio. Ahora bien, para Plutarco, la cultura, y concretamente la filosofía, son un ingrediente esencial del buen gobernante; baste remitir a determinados pasajes del ad principem indoctum ${ }^{14}$. La postura antifilosófica e inculta de Catón hace de él, por tanto, un mal gobernante. Plutarco no explicita esta conclusión. Tampoco utiliza la $\varphi \imath \lambda \alpha v \theta \rho \omega \pi i ́ \alpha$ para descalificar de manera directa a su protagonista. Pero la actuación de éste se contrapone a la de aquellas audiencias que escuchaban, llenas de $\varphi \imath \lambda \alpha v \theta \rho \omega \pi i ́ \alpha$, al filósofo Carnéades. Quizás no carezcan de intención las menciones de dos tiranos, Pisístrato y Dionisio de Siracusa, insertas en el pasaje que relata el segundo matrimonio de Catón ${ }^{15}$.

El apego de Catón a las riquezas también aparece en la síncrisis, donde

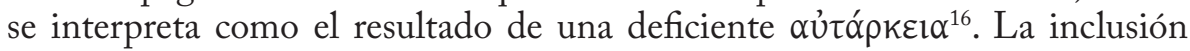
en un lugar tan destacada como este delata la importancia que reviste el tema

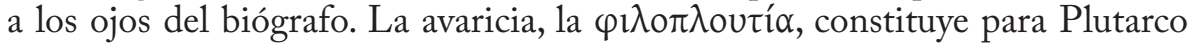
un grave defecto, según muestran las observaciones contenidas en el tratado de cupiditate divitiarum. Dejando aparte dichas observaciones, que atañen

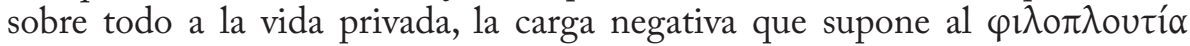
para el dirigente se indica refleja en dos pasajes de los precepta gerendae rei

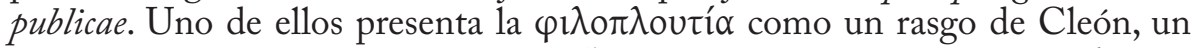

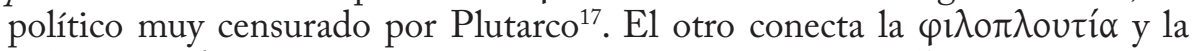

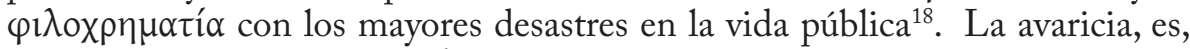
igual que la falta de $\sigma \omega \varphi$ oóv $\eta$, una lacra que colorea muy negativamente la personalidad de Catón como político. Ambos defectos se mencionan en la síncrisis, y los pasajes narrativos que los presentan y detallan hacen en ambos casos una mención explicíta del concepto de $\varphi \imath \lambda \alpha v \theta \rho \omega \pi i ́ \alpha$.

Hay una tercera mención explícita del concepto de $\varphi \imath \lambda \alpha v \theta \rho \omega \pi i ́ \alpha$ en la $V i d a$ de Catón. Durante la segundo guerra púnica Catón fue nombrado cuestor bajo las órdenes de Escipión Africano, cónsul a la sazón. Escipión efectuaba en Sicilia los preparativos necesarios para desembarcar en África y Catón, al observar la prodigalidad con que el cónsul gastaba los fondos públicos y su lujoso tren de vida, presenta una denuncia en Roma. Dos tribunos llegan de Roma para verificar la exactitud de la denuncia. Escipión entonces justifica los gastos con la perspectiva de la victoria y hace ver que si durante los momentos de ocio comparte con sus amigos dulces experiencias, su dedicación a los asuntos serios e importantes no queda mermada por ese régimen de vida "filantrópico"19. Aparentemente, tampoco aquí se percibe un uso político del

${ }^{14}$ Véase, por ejemplo, 779D; 780A; 781A

${ }^{15}$ Pisístrato: 24.8; Dionisio: 24.11.

${ }^{16}$ Cat. Ma. 31 (4).2-4.

${ }^{17}$ Praec. ger. rei. 806F. Sobre la valoración que hace Plutarco de Cleón véase G.J. D. Aalders, 1982, p. 30 .

18 Praec. ger. rei. $819 \mathrm{E}$.

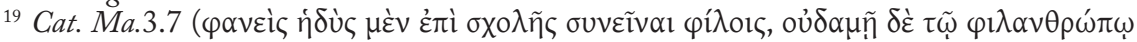

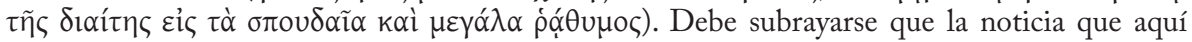


concepto de $\varphi \imath \lambda \alpha v \theta \rho \omega \pi i ́ \alpha$, concepto que además, como ocurría en la narración de las conferencias de Carnéades, se atribuye al adversario de Catón, pero no se niega a Catón mismo. Plutarco tampoco hace, de momento, comentario alguno sobre este enfrentamiento con Escipión. Pero en la síncrisis el episodio es recordado y utilizado como argumento para una acusación de peso: con su ataque a Escipión Catón perjudica la guerra contra Aníbal ${ }^{20}$. Una vez más un pasaje marcado por la presencia aparentemente inocua del concepto de $\varphi 1 \lambda \alpha v \theta \rho \omega \pi i ́ \alpha$ da lugar a una condena severa del protagonista.

La Vida de Catón no es una biografía negativa. A Plutarco le habría sido muy difícil ennegrecer por completo la figura de este personaje, cuya memoria, adornada con los perfiles de exemplum tradicional, había pasado a ser todo un paradigma de las virtudes romanas ${ }^{21}$. Pero determinadas actuaciones del protagonista de la biografía, y especialmente su antihelenismo, constituían una mácula difícil de pasar por alto. De aquí que en su retrato convivan las notas aprobatorias con fuertes reservas. Quizás la expresión más elocuente de esta actitud matizada y ambivalente se da en el capítulo sexto, que comentando el rigor desplegado por Catón como pretor en Cerdeña afirma que la administración romana no fue nunca ni más temida ni más deseada ${ }^{22}$. Plutarco, en suma, se siente con la libertad suficiente para emitir un juicio distanciado que, sin ser negativo, tampoco ahorra las críticas. En este sentido la Vida de Catón parece confirmar aquel punto de vista según el cual la historia de la república se convierte, con el advenimiento de Trajano, en historia antigua, es decir, en un ámbito lo suficientemente lejano como para permitir opiniones ajenas a la disensión política y, por tanto, libres y distanciadas ${ }^{23}$ : si no había contradicción en presentar como héroes tanto a César como a sus ejecutores, tampoco lo había en admirar a Catón y, al mismo tiempo, desautorizar sus actuaciones.

Esa desautorización actúa, si la tesis aquí propuesta se admite, mediante la incrustación en pasajes clave del término $\varphi \imath \lambda \alpha v \theta \rho \omega \pi i ́ \alpha$, que marca en el ambiente ideológico donde se encuadran las Vidas Paralelas una virtud política imprescindible. Plutarco, por otra parte, emplea el término $\varphi \imath \lambda \alpha v \theta \rho \omega \pi i ́ \alpha$ de manera aparentemente casual, como si se pretendiera restarle importancia. Ello puede atribuirse a la preferencia del biógrafo por una escritura de tono bajo, que evita subrayar los puntos candentes de la actualidad y que busca conferir a sus palabras un manto de intemporalidad ${ }^{24}$. Cabe también formular tal preferencia con otras palabras. La escritura de Plutarco conforma un texto complejo y polisémico en el que proliferan las alusiones, los guiños al lector,

transmite Plutarco es posiblemente falsa, siendo su fuente de inspiración el conflicto que mantuvieron Escipión y Catón a partir del 180: véase A. A. Astin, 1978, pp.14-6.

${ }^{20}$ Cat. Ma. 32 (5). 4.

${ }^{21}$ Sobre Catón como ejemplo de virtudes romanas véase S. Agache, 1980. La misma autora (pp. 95-8) habla de una "leyenda negra" (aunque de matices moderados) sobre Catón en cuyo contexto sitúa la crítica de Plutarco.

${ }^{22}$ Cat. Ma. 6.4

${ }^{23}$ J. Geiger, 2002, p. 97

${ }^{24}$ Véase P. A. Stadter, 2002b, pp. 236, 238; C. B. R. Pelling, 2002, pp. 215, 222. 
los sobreentendidos y las indicaciones oblicuas. Lo que parece casual puede ser, en realidad, determinante, y una observación carente a primera vista de importancia puede ser la clave sobre la que descansa una interpretación cargada de consecuencias. Tal vez deban entenderse bajo esta óptica las apariciones del concepto de $\varphi \imath \lambda \alpha v \theta \rho \omega \pi i ́ \alpha$ en la Vida de Catón el Viejo.

\section{Bibliografía CITADA}

Aalders, G. J. D., Plutarch's Political Thought, Amsterdam, 1982.

Agache, S., "Caton le Censeur, les fortunes d'une légende”, Caesarodonum, 15 (1980) 71-107.

Andrei, O., "Demetrio Poliorcete secondo Plutarco: Da una 'grande natura' a 'grandi' vizi", in Vite parallele. Plutarco. Demetrio (introduzione, traduzione e note di O. A.); Antonio (introduzione, traduzione e note di R. Scuderi), Milano, 1989, pp. 35-93.

Astin, A. A., Cato the Censor, Oxford, 1978.

Candau, J. M., "La Vida de Demetrio como biografía negativa", in J. G. Montes Cala et al. (eds.), Plutarco, Dionisio y el vino. Actas del VI Simposio Español sobre Plutarco (Cádiz, 14-16 de Mayo, 1998), Madrid, 1999, pp. 139-44.

Cervantes Mauri, J.M., "La virtud de los animales en el Gryllus de Plutarco", in Jufresa, M. et AL. (eds.), 2005, 265-272.

Clavo Sebastián, M. T., "El Grilo y la sátira del humanismo en Maquiavelo y Gelli”, in Jufresa, M. ET AL. (eds.), 2005, 693-702.

D’Ippolito, G., "Filantropia, ellenocentrismo e polietnismo in Plutarco", in A. Pérez Jiménez \& F. Titchener (eds.), Historical and Biographical Values of Plutarch's Work. Studies Devoted to Professor Philip A. Stadter by The International Plutarch Society, Málaga - Logan, 2005, pp. 179-96.

Duff, T., "Plutarch, Plato and 'Great Natures", in A. Pérez Jiménez et AL. (eds.), Plutarco, Platón y Aristóteles. Actas del V Congreso Internacional de la I. P. S. (Madrid-Cuenca, 4-7 de Mayo de 1999), Madrid, 1999, pp. 313-32.

Geiger, J., "Felicitas Temporum and Plutarch's Choice of heroes", in P. A. Stadter \& L. Van der Stockt (eds.), 2002, pp. 91-102.

Georgiadou, A., Plutarchs' Pelopidas. A Historical and Philological Commentary, Stuttgart und Leipzig, 1997.

Jufresa, M. et Al. (eds.), Plutarch a la seva època: paideia e societat. Actas del VII Simposio Español sobre Plutarco (Barcelona, 6-8 de Noviembre de 2003), Barcelona, 2005. 
Pelling, C. B. R. , "Plutarch's Caesar: A Caesar for the Caesars?", in P. A. Stadter \& L. VAn der Stockt (eds.), 2002, pp. 213-26.

Schettino, M.T., “Trajan's Rescript de bonis relegatorum and Plutarch's Ideal Ruler", in P. A. Stadter \& L. VAN Der Stockt (eds.), 2002, pp. 20112.

Stadter, P. A., "Introduction: Setting Plutarch in his Context", in P. A. Stadter \& L. VAn der Stockt (eds.), 2002a, pp. 2-26.

"Plutarch and Trajanic Ideology", in P. A. Stadter \& L. VAn Der Sтоскт, (eds.), 2002b, pp. 227-41.

\& VAn der Stockt, L. (eds.), Sage and Emperor. Plutarch, Greek Intellectuals, and Roman Power in the Time of Trajan (98-117 A.D.), Leuven, 2002.

Teodorsson, S.-T., "Four Terms of Friendly Emotion in Plutarch:

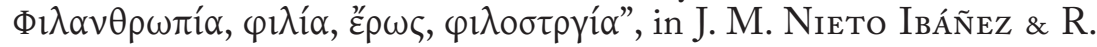
López López (eds.), El Amor en Plutarco. Actas del IX Simposio español sobre Plutarco (28-30 de Septiembre, 2006), León, 2007, pp. 187-97.

Zecchini, G., "Plutarch as Political Theorist and Trajan: some reflections", in P. A. Stadter \& L. Van Der Stockt (eds.), 2002, pp. 191-200. 